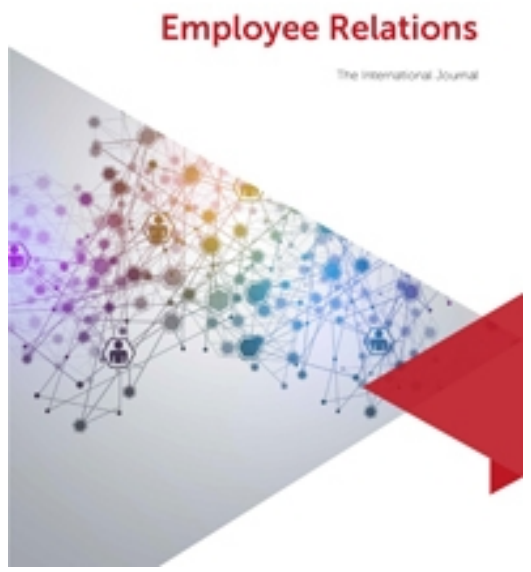

Working with Emotions: Cultural Employee Perspectives to Service Management Expectations

\begin{tabular}{|r|l|}
\hline Journal: & Employee Relations \\
\hline Manuscript ID & ER-11-2020-0489.R1 \\
\hline Manuscript Type: & Research Paper \\
\hline Keywords: & $\begin{array}{l}\text { Working with emotions, Service employees, Nigerian call centre, Emotion } \\
\text { and culture }\end{array}$ \\
\hline
\end{tabular}

\title{
SCHOLARONE \\ Manuscripts
}




\title{
Working with Emotions: Cultural Employee Perspectives to Service Management Expectations
}

\begin{abstract}
Purpose - Drawing on emotional labour theory, the purpose of this paper is to explore the effects of cultural orientation on emotion regulation and display processes for service employees.

Design/methodology/approach - Based on a Nigerian study where literature is scarce, data was gathered from semi-structured interviews conducted with 40 call centre service agents.

Findings - The findings identified three key values around reinforcing social cohesion, anticipated self-curtailment, hierarchy and expressions of servility based on broader societal needs to promote relational harmony when managing customer relations during inbound calls into the call centre.

Research Limitations/implications - The extent to which findings can be generalised is constrained by the limited and selected sample size. However, the study makes contributions to service work theory by identifying the extent to which communication of emotions is informed in large parts by local culture and seeks to incite scholarly awareness on the differences of emotional display rules from a developing country other than western contexts.
\end{abstract}

Originality - This paper is among the first to focus on the interface between culture and emotion labour from a Sub-Saharan African context.

\section{Introduction}

There is growing scholarly interest in assessing emotional labour (EL) requisitions as a key component of customer service work (Jeong et al., 2019). Call centre frontline employees are expected to regulate and display appropriate emotions via vocal cues (Jaarsveld and Poster, 2013). Many call centre studies conducted in several countries share the mandatory "service with a smile" rule. However, a cultural perspective suggests a possible influence of context on emotion regulation necessary for EL demands (Nixon et al., 2019) - an area of work that is still at a nascent stage and where literature gap exists (Ford and Gross, 2019). Here, scholars (e.g. Ma et al., 2018) have argued that regulating emotions and expressive feelings are often a function of societal and organisational norms. The extent to which services are further influenced by broad-ranging societal beliefs and geographical location introduces more complexities in EL practices. Understanding the significance of cultural norms is important given that, as a global business strategy to reduce labour cost, service-based organisations in the UK and the United States are either outsourcing or moving their call centres to low-income economies such as India and Canadian centres to the Philippines (De Leersnyde et al., 2013). Employees may accordingly be required to perform emotional displays that are incongruent with cultural norms. Against this background, this article undertakes an empirical analysis of frontline call centre service agents' perspectives on the extent to which emotion regulation and service display are systematically shaped by local culture which represents a literature gap that this study aims to fill. Specifically, in the under-researched context of Nigeria, this study addresses the following research question (RQ):

RQ: To what extent do cultural context influence emotion regulation and expressions in call centre operations?

Significantly, what is known about emotional labour (especially in call centre work) is mostly from Western cultures (Mann, 2007; Burgess et al., 2018; Chicu et al., 2019) and Asian 
countries (D'Cruz and Noronha, 2008; Gain, 2011). Similar studies particularly from the African continent are rare despite successful development of call centres in these emerging markets. Focusing on Africa, Nigeria is a major market for telecommunication equipment and services (Adebisi, 2011). It is one of the most populous nations in Africa, and has captured the attention of global ICT investors and well noted for inroads made by multinational telecommunications firms because of the nation's large customer base. Jaarsveld and Poster, (2013), suggests that researchers can draw from this mainstream context to examine whether emotion work operates the same way for the workforce as it does for call centre samples in the west. From this perspective, this paper becomes timely to both researchers and practitioners seeking further clarification on how cultural orientation impacts on EL by providing empirical evidence from the global south.

\section{Theoretical background and framework: Emotion regulation and emotional labour}

Emotional labour research has increasingly delineated emotion regulation and expression to involve a careful control of emotional fronts presented to customers and clients (Grandey et al., 2010). Gross (1998, p. 275) defines emotion regulation as "the processes by which individuals influence which emotions they have, when they have them, and how they experience and express these emotions. Emotion regulatory processes may be automatic or controlled, conscious or unconscious, and may have their effects at one or more points in the generative emotion process". Organisationally prescribed rules are presumed to guide emotion regulation and are known as sets of standards propelling impression management (Mann, 2007). Scholarly discussions on internal processes of regulating both feelings and expressions in line with organisational directives are integral to EL which is an essential part of frontline occupations.

In her classical text - 'The Managed Heart', Arlie Hoschschild (1983) defined EL as the "management of feelings to create a publicly observable facial and bodily display" where such labour is sold for a wage and therefore has exchange value. Hochschild considered the mandatory performance of EL to involve two forms of self-regulatory strategies, referred to as deep acting and surface acting. Deep acting was conceptualised as occurring when service employees consciously changes feelings in order to express desired emotions, through subconscious activities such as cognitive reappraisals, positive refocussing, and psychological modification of the mind favourably (Hochschild, 1995). Surface acting on the other hand, involves feigning or simulating feelings by supressing felt emotions which requires considerable effort to maintain and sometimes strenuous to sustain. Since the introduction of EL by Hochschild, efforts to redefine and theoretically expand the concept have been made by many scholars. For instance, Ashforth and Humphrey, (1993) proposed a perspective operationalising EL as "the act of displaying the appropriate emotions". As a contribution, these authors reframed Hochschild's feeling rules to display rules by emphasizing more on the external observable behaviours (that is - what is displayed) rather than the presumed emotions underlying the behaviour. However, Ashforth and Humphrey further asserts that service engagements tend to be repetitive and constitutes manipulation of outward behaviours that should constantly conform to formalised service protocols.

Of the antecedents that affect EL, Morris and Feldman, (1996, p. 987) defined EL as "effort, planning, and control required to display organisationally desired emotions during interpersonal transaction". They argued that EL in service work is primarily shaped by the following four dimensions - the frequency, duration, intensity and emotional dissonance which are recognised as predicting adversarial impact or otherwise of controlled emotions during service interactions. Contemporary authors (e.g. Grandey et al., 2010; Gross, 2015) largely conform to this psychological perspective seeing EL as requiring service employees to either 
induce or suppress emotions in order to sustain outward countenances meant to produce a proper state of mind to customers. In most cases, the actor has learnt to psychosocially intervene - either by creating inner feelings or altering expressive demeanours. In proposing an extended process model of self-regulatory behaviours, Gross (2015) argues that the three emotion regulation stages of 'identifying, selecting and implementing' these psychological displays can either be helpful or harmful depending on the circumstances and type of service.

Much of the literature suggests that intense and continuous conformity to EL expectations can be stressful and exhausting because it constantly requires servers to portray emotions that are not felt, creating strain and emotive dissonance (Tsang, 2019). These display rules in customer service organisations (like call centres) are usually communicated via formal service policies, scripted dialogues as well as through automated workflow monitoring with negative implications for feelings of autonomy (Subramanian and Suquent, 2018). Despite the breadth of findings on the dimensions of emotionality from a psychological perspective captured in our literature review, there have been limited attempts to develop a rigorous understanding of the sociological nature of EL, especially from a cultural context which have profound implications for EL research. This represents a significant gap which this article seeks to address. While past and extant literature have repeatedly associated emotional EL with psychological consequences, a cultural perspective may suggest, however, that these consequences may be regulated by cultural values that are mostly overlooked in EL research (Butler et al., 2007; Mastracci and Hsieh, 2016; Haslam et al., 2020). As such, this paper takes advantage of this important gap, and yet again from a developing country (i.e. Nigeria) where mainstream literature appears non-existent. This is important considering the development of the telecoms and information technology service sector across the continent.

\section{Culture and Emotional Labour}

As Soto et al., (2011) argue, culture shapes self-regulatory behaviour so that emotion regimes do not exist in isolation. Regulating emotions, and expressive expectations accordingly vary with cultural context (Grandey et al., 2010). Culture is defined as "a unique meaning and information system, shared by a group and transmitted across generations" (Matsumoto, 2007, p. 1286). On the emotional front, it creates guidelines and reinforces emotional responses sanctioned as preferred common expressions accepted in one country and rejected by another (Jaarsveld and Poster, 2013). Culture also preserves the collective identity and social order of societies (Matsumoto et al., 2008). As a result, it has been shown that societal norms shape interpersonal interactions in service-orientated jobs and results in compliance with both particular "feeling rules" (that is how emotions should be experienced) and "display rules" (what emotions to express and those to hide) irrespective of service delivery mode (Wice et al., 2019). This literature notwithstanding, only limited attention has been given to the role culture plays in framing feelings and expressions portrayed in EL.

Further, although some research has looked at the relationships among EL constructs (such as surface and deep acting) from western cross-cultural perspectives (Allen et al., 2014), little is known about how specific cultural orientation shapes regulation and display of emotions necessary for EL peculiar to service organisations in non-western contexts. For instance, Grandy et al., (2005) in a cross-cultural research reported in Allen et al., (2014) explored how EL enactments differ between United States and France. Findings emerging from their study revealed that the connection between emotion regulation and job dissatisfaction was weaker among French service workers than those of the U.S. This reflected a more impulsive orientation among the French towards emotion display where emotional autonomy is permitted while U.S. service employees were found to cultivate an institutional orientation that makes them culturally connected to their employments, expressing emotions which aligns with 
institutional obligations. Looking at customer service-orientated jobs, Grandey et al., (2010) found that "service with a smile" was uniformly accepted across all cultures, but these values were more strongly reflected in the US, perhaps in reflection of its diversity whereas Allen et al., (2014), found, emotional expressiveness may positively correlate with heterogeneity.

In another paper, Mann (2007, p. 563) compared expectations that the Americans and Britons have towards emotional displays from service workers and work colleagues. It was found that the British expected more positive displays from people they encounter during service transactions (e.g. supermarket attendants, shop assistants and fast-food servers) than from colleagues while the reverse was the case in the US. Comparing the US with Japan, Matsumoto et al., (2008) found that it was easier for the Japanese to mask stressful feelings with positive expressions. Taken together, this points to the significance of culture for emotional regulation and expression. Thus, Nigeria has been seen as less individualistic than western contexts where individuals seek to define themselves as members of a social group (Hofstede, 2001). Here, strong ties and mandatory obligations to extended relationships are prioritised far above individual achievements and personal aspirations (Jackson, 2004). Other everyday traditional features in the country include acceptance of hierarchy, gender inequality and status differentials especially at the workplace (Mordi et al., 2013), all of which are likely to impact on how emotional labour is performed.

\section{The study context}

The Nigerian call centre sector thrived rapidly after the government privatised the Nigerian telecommunications industry in 2001. This gave business rights to various ICT multinationals and allowed local investors to engage in telecoms services, wireless operations and ancillary businesses (Adebisi, 2011). The result was the creation of call centre employment. These jobs are labour intensive in Nigeria because of the large customer base of various mobile network companies operating in the country (Pyramid, 2010). The Nigerian mobile telecommunications service is one of the fastest growing markets in Africa with mobile phone subscribers almost reaching 129 million out of the estimated population of about 198 million (CIA World Factbook 2017). These call centres are located in major commercial cities in Nigeria, set up to deal with inbound customer queries and complaints relating to mobile phone services. Some of the leading telecoms brands in Nigeria are the South African owned MTN (Mobile Telecommunications Networks), 9mobile (owned by Nigeria and other foreign investors), Globalcom (indigenously owned by a Nigerian) and many other providers that gained entry through foreign direct investment.

The Nigerian call centre industry has grown exponentially as a result of the large customer based as well as the employment opportunities given to a large pool of computer-literate university graduates with good English communication skills. There has always been a strong emphasis on educational attainment in Nigeria because the popular belief is that acquiring a formal education gives young Nigerians the opportunity to earn an income to cater for their old parents and siblings since Nigeria as a collectivist culture define themselves in terms of group membership (Akanji et al., 2020a). Being a society that values collectivism, people relate to one another interdependently by maintaining strong social and family ties as opposed to individualistic cultures where individuals are independent and free from relying on others, but rather strive to promote uniqueness and inherent abilities to stand out among others (Hofstede, 2001). As such, interpersonal relations in collectivist cultures seeks to promote cooperation and temperance with others within the various social settings ranging from family structures, workgroups and ethnic tribes (Henchanova 2013). The influence of collectivism in the context of call centre work presents an important research inquiry of exploring how Nigerian service 
agents draw on their local cultural context which inevitably shapes emotion regulation aimed at offering the right service to customers who are also Nigerians.

\section{Research methodology}

The qualitative design used in this study draws from an interpretive-social constructivist tradition that places emphasis on lived experiences (Saunders et al., 2015). The philosophical assumption of a social constructivist paradigm is the belief that peoples' expressed thoughts are more vivid from their verbal accounts and also reveals "taken for granted assumptions" about social reality (Bowen, 2008). This was thought to be an appropriate approach to explore experiences of performing emotional labour.

\section{Data collection}

Placing reliance on subjective judgements, a non-probabilistic purposive sampling was used to recruit 40 Nigerian call centre agents comprising of both genders. According to Patton (2015), the rationale for engaging purposive sampling is based on the suppositions that the researcher has a reasonable knowledge of the sample size to be used and as a result targets those particular samples. The sites visited were one of MTN's call centres located in Lagos and another owned by 9mobile network based in Abuja. Lagos is Nigeria's largest commercial city while Abuja is the Nigerian Federal Capital Territory with growing numbers of call centres spread across the city. Both centres revealed telephone agents working in a highly pressurised and noisy environment receiving inbound calls and controlled by automatic call distribution systems.

The researchers observed team managers' use of predictive dialling systems to control the pace, quality and length of service interactions. A scripted dialog must be followed and agents mandated to convey positive emotions at all times through voice, tone and inflections. Convincingly, the call centre working conditions at both sites visited confirms the views of Fernie and Metcalf (1997) who in the past described call centre work as a type of "electronic panopticons" due to the narrow job design and intensity of EL required. Participants of this study were solicited through emails, personal contacts, referrals and a snowballing approach. Eligibility for participation was based on length of work experience (minimum of one year), educational level (i.e university undergraduates and graduates) and desire to take part in the study. Their ages were between 25-35 years as these sets of agents were presumed to be more experienced by their managers. They worked flexible shifts. The semi-structured interviews with all participants (labelled agent 1-40) lasted between 45 to 60 minutes after obtaining prior consent from participants and their employers.

The nature of the interview style, based on open ended questions, gave room for flexibility in discussions, allowed individual perceptions and experiences to be explored and facilitated identification of participants' verbal and non-verbal dispositions. We interviewed 27 agents in Lagos while the remaining were based in Abuja. Interviews were conducted on-site so that research findings could be contextualised. In terms of assessing the reliability of the study, the researchers met frequently after individual sessions to compare interview notes and ensure all interview protocols were covered so that dependability on the collected data would not be compromised (Corley and Giola, 2004). Interviews explored the nature of emotions expressed during calls from customers; expectations from employers in terms of customer engagement; how emotions were modified; how individuals conformed to or resisted expected forms of emotional expression (from employers, from customers); and most importantly, cultural norms that were seen to influence these forms of engagement.

Given the semi-structured nature of interviewing, questions were modified based on participants' responses and answers that were audio-recorded. In keeping with the request for 
confidentiality, all interviewees and call centres were anonymised. After 35 participants had been interviewed, it was felt that 'saturation point' had been reached in that no information was added that could further enhance the findings from the study (Bowen, 2008). To confirm this position, five further interviews were undertaken to corroborate existing themes.

\section{Data analysis}

Interviews were transcribed and analysed thematically (TAP). TAP is a qualitative design employed to identify, analyse, and report patterns (themes) within data sets (Braun and Clarke, 2006). This was done by adopting three major steps following Pratt et al., (2006) and Lincoln and Guba's (1985) qualitative approach. First, we highlighted initial concepts in the data sets (i.e. language used by participants) via first-order codes. More specifically, this open coding system involved analysing textual content and creating two lettered words or simple descriptive phrases that symbolically assigns a salient, summative and essence-capturing attribute of interview extracts directly addressing our study inquiry (see Figure 1 below).

\section{Insert Figure 1 here}

Our contact summary forms were specifically used to record the provisional codes revealed in each interview at each point in time. For instance, there were data fragments that related to one of the representative questions asked - How do you try to adjust your feelings to social norms and expressive expectations as a call centre agent? In addressing this question, 'tentative descriptions' from data chunks suggesting 'expressions of self-denial' and 'anger avoidance feelings' characterises emotional moderation geared towards promoting relational values by avoiding disruptive interactions with customers (see illustrative quotes in Figure 1). After all codes were named and categories were constructed, we reviewed the interview data to evaluate important narrative accounts and to ensure extracts fitted each coded foci appropriately.

Secondly, we consolidated first-order codes in creating theoretical categories. It was done by consolidating first-order codes emerging from interview data sets (see Figure 1). This made the first-order coding 'more theoretical and more abstract' (Pratt et al, 2006, p. 240). In the third and final step, we consolidated our conceptual categories in a bid to generate theoretical explanations for the occurrence of the phenomenon understudy. In arriving at this, a process of cross-comparison and validation of conceptual categories continued until consensus was reached on what should constitute the main themes of the study. This is the last phase of the research analysis in establishing theoretical claims grounded in the data (Miles et al., 2014).

In ensuring trustworthiness of qualitative data as recommended by Lincoln and Guba (1985), we conscientiously managed our data, including the manual contact summary forms and interview transcripts and field notes by recording them electronically as a backup. We also engaged in peer debriefing and agreed to invite other researchers not involved in the study to scrutinise our analysis procedures and authenticate its validity (Corley and Giola, 2004). Giving more details, we invited two experienced qualitative experts to independently review our coding and categorisations. The researchers independently coded a random sample $(15 \%)$ of the interview transcriptions to assess the reliability of the categorisation scheme. We calculated inter coder reliability using Cohen's (1960) kappa. The result of inter-rater reliability between primary coding and secondary categorisations (Kappa 0.92) showed a high level of agreement which is well above the minimal threshold (kappa 0.70) suggested by Cohen (1960). From our analysis, three interrelated themes emerged that relate to a need to reinforce social cohesion, anticipated self-curtailment and, hierarchy and expressions of servility.

\section{Reinforcing social cohesion}


Half of the participants emphasized how the need to promote social cohesion as a societal tradition influences emotion and voice expressions during service encounters. In contrast to the greater individuality of the west, Nigerian culture was recognised as promoting harmony and cooperation within groups. This was seen to manifest in less assertive tones and voice inflections when speaking to customers, symptomatic of a 'relational embeddedness' of emotion regulation to reinforce social cohesion (see Figure 1). This was particularly marked given the transitory nature of the contact with customers where norms of engagement dictate a particularly deferential tone of communication and expression. Primacy was also given to group (e.g. family) belonging:

Since our culture encourages exhibiting etiquettes to strangers encountered for the first time, I perceive this tradition influences emotions that requires me to align my tone, language and attitude to compulsorily portray humility, benevolence and community-kind of service that our customers will appreciate any time they call in (Agent 8).

Our call centre service culture is a function of our societal expectations to treat everyone as family members which makes me convey positive emotions that gives our customers a sense of belonging to MTN's big family even if it means hiding any ill feelings during interactions (Agent 9).

Having worked here for five years, I believe interactive values makes us compulsorily regulate our feelings even if it means sacrificing our own happiness to please customers calling in from villages and cities in Nigeria with our network coverage (Agent 10).

Agents reveal particular 'cultured expressions' (see Figure 1) as a salient concern governing appropriate emotion regulation in providing good service where EL is seen largely in terms of fostering interpersonal relations (Allen et al., 2014) and where societal values are seen to influence what emotions ought to be expressed as well as those that should be concealed (Mann, 2007). As such, these shared views describe emotions as interactive experiences that relegate personal aggrandisement (Cheung and Irene, 2010). A major part of the fabric of the Nigerian society is its collectivist system (Akanji et al., 2020b) that emphases obligations to others in terms of their aspirations and well-being and where deference and 'lower self-hedonism' are strongly supported:

As a cultural expectation, when I am dealing with enraged customers over the phone, I am always expected to comport myself especially to those who I have never spoken to before and not sound agitated as well. We believe you cannot engage in harsh response to address rude customers (Agent 11).

As a culture, you need to sound modest to callers [...] sounding excessively cheerful or playful may be interpreted as rudeness sometimes (Agent 12)

These perspectives parallels with few cross-cultural studies suggesting emotional moderation as a culturally observed tradition in collectivist countries similar to those found in China, India, Korea, Taiwan and Japan (see Eid and Diener, 2001; Matsumoto, Yoo and Nakagawa, 2008; Grandey et al., 2013). According to Eid and Diener (2001, p. 883), "in China, there is a general attitude to consider emotions as dangerous, irrelevant, or illness causing [...] the moderation or suppression of emotions is generally highly valued in China". In contrast, Western cultures (e.g. the U.S.) tend to value self-expression. Thus, Santos et al., (2015), observed that people in individualistic cultures tend to regulate emotions as autonomous expressions differently from those in collectivist societies where emotional displays exist as a way to maintain social cohesion even at the expense of oneself (summarized in the first order codes). 
As a counter-point, a small minority (about 11\%) of mainly younger participants were less inclined to follow socio-cultural or organisational regulatory conventions that encouraged them to be less assertive:

I find all this talk about upholding traditional cultural attitudes such as being guarded in language, tone, behaviour or choice of words as old, out of touch with we young peoples' realities. All these old managers don't understand the world has changed. We are always told the customers are king, the boss too is king ... what about us, I mean workers are we slaves? These emotional regulatory mechanisms are all manipulative ways of shackling us (Agent 13).

...sometimes I feel really concerned when our service protocols always have to conform to our cultural inclinations that places more emphases on people than personal assertive behaviours. At 26, I'm of the generation that feels that always maintaining social relations with customers always makes some of them look down on us. My manager sometimes pulls me off the phones to scold me or threaten me with a pay cut when I'm blunt with uncooperative customers (Agent 14)

Our service values places high regard in promoting cooperation and social ties with our inbound MTN callers which is in tandem with our native culture but makes connection with our inner self less important...I sometimes hate this approach but the fear of being sacked or called a deviant makes me a conformist (Agent 15)

From the above, workers who do not conform to proper societal emotional regulative protocols are sanctioned and corrected (the above agents was threatened with salary deduction and dismissal). There were also claims that erring workers have been sent on training courses and have also been corrected using structures away from the work milieu, drawing on the support of nuclear and extended family members, friends or religious ministers - symptomatic of the high level of pressure to conform. These cases notwithstanding, results suggest as Eid and Diener (2012) argue, that emotion and impression management may be perceived as less dependent on organisational specific display rules (such as - 'always smile at the customer') in this context and more reliant on relational values that accord with a more collectivist culture and which are accepted and well- practiced in everyday life.

\section{Anticipated self-curtailment}

For $29 \%$ of participants, there was agreement that as service agents, call centre managers expects higher emotional labour engagement with customers by constantly curtailing one's true feelings is perceived as appropriate to express caring attitudes. In other words, perpetually suppressing emotions (i.e. making self-curtailment a habit) was said to portray friendly service. In serving as a buffer against emotional dissonance normally associated with surface acting, agents explained that they often try to sound calm and content which had a reciprocal effect in that customers were likely to respond in a similar manner. There were claims that they constantly engaged response-focused emotion regulation which involves prolonged and restrictive ongoing emotional experiences (Narh and Akdemir, 2019) for the sake of treating callers with respect as one will treat a family member in this context. This was supported by visible displays of cultural values through slogans, large stickers and posters on call centre walls with words such as 'treat every caller like family', 'tolerate strangers', 'respect elderly customers', 'customers are always right' and 'refrain from anger'. As such, curtailing emotions (see Figure 1) emerged as a relational phenomenon embedded in prioritising concerns of others and perceived to reflect the state of those relationships (Mastracci and Hsieh, 2016). These obligations were met by ensuring every customer receives care and attention (exemplified in statements such as 'I always empathize and express overwhelming care', 'showing an extremely caring attitude' - Figure 1). 
In keeping with our tradition of treating others with care, I show a high level of attention, interest and willingness to help customers solve their network or phone problems. Sounding nice and friendly to people knowing 'customers are always right' is a value added part for selfregulating my feelings to conform to relational needs of business interactions (Agent 16).

The desire to show 'customer care', friendliness and goodwill and to create a good impression were seen as each agent's self-regulatory effort and the influence of cultural values on such displayed emotions as an integral part of call centre service. This could encompass expressed concern for the welfare of friends and family of customers during exchange of salutations at the beginning of calls - going beyond a unitary focus on the business at hand to encompassing the broader social wellbeing of customers through a relational exchange. Good service is accordingly not seen purely in terms of service efficiency and time saving protocols that appears more valuable in the West (Grandey et al., 2010), but as goodwill and personal attention to customer needs and requirement even if it means active reduction of emotions and expressive behaviours to portray service manners. This situation is instantiated below:

I always want customers to feel at ease with me even if they sound moody - so I sometimes ask polite questions about the customer's observations about the weather today or general questions about their state of wellbeing even if I'm not in the mood to engage customers in such mundane conversations (Agent 17).

Since we have a tradition of looking after one another in our country, it shapes my expressions of always sounding helpful and happy to resolve customer complaints over the phone knowing fully well that difficulties with mobile phone reception in Nigeria is quite recurrent and makes customers very angry but you still have to keep your cool always (Agent 18).

Generally, cultural and service rules forbid getting angry at a customer no matter how annoying they sound when handling inbound calls. So I restrain my emotions so that the public image of our brand and customer care values are not compromised. More so, I do not want customers to feel bad or have a wrong impression of me after the call (Agent 19).

The responses above suggest basic underlying assumptions that call centre EL observed, involves compliance with feeling rules gravitating towards deep acting (emanating from cognitive re-appraisal) and surface displays (i.e. suppressing emotions) in order to appear calm and helpful irrespective of any negative feelings towards the customer concerned. Both regulatory modes (i.e. deep and surface acting) may be seen as feasible strategies enacted to achieve relational goals consistent with the interdependent values common to the Nigerian context. As such, handling customers with care meant service agents had to interact politely, regardless of customer aggression (see Figure 1).

While words themselves were said to convey personal suppression of feelings, Nigerians are known to be more interested in what people mean beyond literal interpretations of words used and impressions created during conversation. Thus, emotions can be expressed through linguistic utterances alongside exclamatory expressions (e.g. loudness of voice) with the aim of showing strong empathy. One agent summarised as follows:

Since we Nigerians are sometimes very expressive, language with exclamations such as "Awww", "Eiyaah", "sorry", "oh no" and so on are some common slangs we are allowed to use in sounding caring and identifying with customer plights (Agent 20)

This empathetic use of language has its origins in the way indigenous African communities care for a whole community, captured in the proverb: "it takes a village to raise a child" and where appearing pleasant and calm is given value when dealing with people (Tsai et al., 2006). Studies have shown that people from interdependent cultures often are required to suppress emotions to meet expectations of others (Mesquita and Delvaux, 2013). Consistent with this 
view, Butler et al., (2007) argue that Asian countries which are mostly collectivists also encourage emotional suppression in order to avoid hurting peoples' feelings and to preserve relationships. Against this backdrop, it is imperative to express positive emotions as a sign of treating customers with care.

My perception of how our culture shapes our service displays rests squarely on my ability to show care in my dealings. You know some of our customers especially those from the Yoruba tribe always speak in proverbs and adages which makes me believe that it is good culture to help others because it may be my turn tomorrow (Agent 21)

From the above, self-regulation is actively encouraged through a caring and empathetic attitude that often encompassed a wider concern for customer's welfare - where contrary emotions were routinely and habitually suppressed. In contrast to service efficiency norms and a focus on self-interest that may dominate western based service interactions (Grandey et al, 2010), good service here is seen in terms of good will and relational values based on the need to preserve relationships and goodwill. Further, most agents did not perceive emotion regulation and displays as an individual's prerogative or responsibility but as part of a wider cultural norm that governs habitual practice. Individual expressions (and suppressions) of emotion were accordingly acknowledged to form part of the collectivist culture of Nigerian society where rules of engagement have a strong community focus based on the need to preserve relationships. The Nigerian experience is in contrast to much of service management research which has considered EL in offshored Indian call centres for example, where agents are often expected to undermine their cultural and linguistic heritage by emulating western accents, adopt English names, indulge in location masking and other national identity management anesthetizations (Nath, 2011). Thus, Nath (2011), found that Indian call centre agents were often stigmatized and stressed as they are compelled to imitate the western style of service interactions with customers.

\section{Hierarchy and expressions of servility}

Cultural values of respect and acceptance of hierarchy were seen by most participants to exert influence on their adherence to deferential displays during telephone conversations. Cultural practices of obedience to 'superiors' accordingly discourages vocal assertiveness (Akanji, 2016). This was helped by demographic details (age, profession) of customers which appear on the visual display unit when a call is received. For example, feelings expressed are aligned to reflect traditional virtues of respect for strangers and senior citizens:

Initially, when I start conversations with a caller, who sounds elderly, I make sure I sound genuinely friendly and respectful by constantly addressing them as 'Sir' for male callers and female callers, I address them as 'Ma' or 'Madam' throughout our conversation (Agent 22).

Callers who are identified as professionals (e.g. medical doctor, lawyer, bank manager) are treated with equal deference and excessive willingness to please and serve:

It is compulsory that I address these customers professionally using expressions such as - 'I quite understand your concerns Doctor Ayo [...]', 'We are sorry, Lawyer Jide for the poor signal strength you are receiving at the moment [...] I can assure you 'Sir' that we are currently spreading network coverage and installing new phone masts to cope with the increasing demands for better service [...], I can see you were wrongly billed Professor Adebayo [...] (Agent 22).

While cultural norms dictate that people highly recognised in society such as village chief, priest/leader in a religious setting and government officials are afforded respect and honour during conversations, it was also recognised that such people in an instrumental sense have more purchasing power and are likely to buy mobile phone products and services and it was 
commonplace to give these sets of customers' preferential treatment (e.g. awarding bonus phone credits or other smaller incentives). Generally speaking, however, importance was attached to moral obligations based on respect for hierarchy in customer interactions including notions of acceptability in terms of vocal expressions and forms of address.

Addressing people by their first names is considered a taboo in our culture. The greeting processes are very important in Nigeria. It is considered wrong to greet a customer passively. So we are also instructed to show affectionate dispositions by exchanging pleasantries and asking about our customer's wellbeing (Agent 23).

Cultural values of respect and obedience accordingly govern service interactions where emotions displayed seek to preserve rather than disrupt status hierarchies. These norms underpin the ways in which agents engage with customers in seeking to promote status based relationships.

\section{Conclusion and implications of study}

This study set out to explore the impact of culture on the regulation and display of emotions in the Nigerian call centre service. There has been limited research on the role of cultural values in shaping EL, with much of the research coming from a psychological perspective. Further, call centres in this context have been largely overlooked in EL literature with a dominant focus of inquiry emanating from the west. In a national context characterised by in-group collectivism, our research highlights how cultural norms dictate forms of engagement that go beyond the globally accepted precept of 'service with a smile' (Grandey et al, 2010). More specifically, as an empirical contribution, our research reveals three interrelated themes (see Figure 1) that relate to an emotional engagement based on a 'relational embeddedness' and the endorsement of social cohesion and harmony - a cultural value that sustains within the transience of the customer relationship in this context; on the promotion of self-curtailment within the service encounter based on reciprocal emotions, goodwill and an ethic of care; and on deference and respect for hierarchy.

These results align with cultural norms and values within the Nigerian context. This foregrounds modesty, deference, obligations to others and an emotional moderation that have been seen to characterise more collectivist societies (Mukherjee and Maheshwari, 2014). Deeply rooted in Nigerian culture, and profoundly influencing everyday behaviour and practice, these values serve to underpin social cohesion and the maintenance of social relations. Therefore, rather than comprising a form of individualised and personal expression as in the west, emotional displays and behaviours in Nigeria both reflect and reinforce these group based, relational norms with implications for how EL is performed. While some younger participants may resist the norms of deference that this involves, this suggests as Eid and Diener (2012) also found, that emotion and impression management in Nigeria are less dependent on organisational specific display rules and more reliant on ingrained relational values that are well- practiced in everyday life and reproduced within the call centre work environment. This is why identity masking in the Indian context with a collectivist cultural heritage can become 'problematic in furthering good relations with customers as callers could become aware of and feel indignant about the perpetuated pretence and direct anger towards frontline employees' (Nath, 2011, p. 722). It is thus safe to conclude that regulating emotions, and expressive expectations in each country vary as a function of individualised cultural context of which identity alterations may reinforce a caller's opposition of call centre agents feigning emotions to reflect a different culture or country other than theirs.

On the theoretical front, findings reveal the importance of incorporating context into emotion regulation and EL research. Current literature has tended to converge around emotion 
regulatory processes as predominantly components of psychological responses (e.g. Hochschild, 1983; Johnston et al., 2019). Our findings serve to confirm that EL, and in fact, all forms of emotion regulation and displays, can only be fully understood in affinity to its cultural context. Thus, cultural values characterized by diffused and mutual obligations in prioritising communality and connected to the need to sustain social cohesion and self-curtailment (see figure 1) shape the emotions displayed within service role context. Cross-cultural research on cultural differences in emotion regulation and impression management often focus on cultural perspectives of 'self' (dependent from others) and 'relating' (interdependence on others) (Mesquita et al., 2014). As our study shows, attending to others and adhering to societal expectations when managing emotions to deliver customer care is a priority among call centre staff working at the frontline.

Explicitly, psychology has highlighted particular micro-level processes such as surface and deep acting as individual mechanisms and processes that underlie emotion regulation in EL research. This however is to neglect the influence of social norms and expectations to which individuals refer in modulating emotional experiences (Von-Scheve, 2012). As we demonstrate, participants generally felt comfortable suppressing emotions, in accordance with cultural norms, for the sake of pleasing customers, in order to show concern for their welfare and to offer appropriate deferential displays. This is in contrast to other western studies which have foregrounded adverse consequences of emotional suppression such as stress, burnout, mental fatigue and retaliatory responses towards customers been served (Wegge et al., 2010). Thus, suppressing emotions is found to a large extent to have more positive implications (e.g. satisfaction, gratification) for a majority of Nigerian call centre employees in a context where, as Mesquita and Delvaux (2013,p. 45) argue, emotional suppression and regulation are "central to interdependent cultural models". Thus, in this context, concern for hierarchy and respect for status differences demand certain emotional restrictions and expressions of servility as routine, habitual practice within day to day interactions; normative values that are reproduced (largely unproblematically) within the call centre service relationship. As we argue, EL must accordingly be seen, not just as an individualised or psychologically rooted display, but as a cultural construct and as a culturally sensitive set of behaviours, attitudes and practices that have profound implications for how we understand the nature of service relationship.

\section{Managerial implications}

From a practical standpoint, since emotion regulation in Nigeria is informed by a broader cultural phenomena, managers and HR practitioners working in call centre service environments should as a policy encourage those societal norms that will facilitate better service performance. The practice of local-interdependent values are sometimes unacceptable in Anglo-American cultures, where work and personal relations are severally separated. Therefore, managing emotions to please others or even spending too much time on a call to promote one's relationship with customers may distract from the service task goals that agents should actually accomplish. The number of calls taken and minimising wrap-up time are also integral features of call centre operations. Thus, adequately trained call centre managers should make agents understand that the interface between local values and time efficiency are integral to good service practice (Grandey et al., 2010). As a policy, training and development that will show how to balance both relational and service-focused task should be prioritised. Notwithstanding, the implication for policy and policy-makers in the Nigerian service context is to understand that cultural values directly predicts social outcomes and fully recognise just how much of EL is dictated by cultural context.

\section{Limitations and future research}


The study has limitations that can be addressed in future research. First, the study draws from a small sample size of only two call centres located in Nigeria, which makes a generalisation of findings difficult. Second, biases that can potentially contaminate findings in this type of study is plausible. Third, the result is based on findings from a single country context. Therefore, future research can rely on quantitative designs that provide more internally valid tests via computational techniques. It would also be interesting to engage in cross-cultural studies that compare EL in African countries with other Western nations.

\section{References}

Adebisi, S. (2011). GSM marketing services providers operations and customer satisfaction in Nigeria: An Empirical Investigation. Acta Universitatis Danubius .Economica, 7(1), 1-20.

Akanji, B., Mordi, C., Ituma, A., Adisa, T. A. and Ajonbadi, H. (2020a), "The influence of organisational culture on leadership style in higher education institutions", Personnel Review, Vol. 40 No. 1, pp. 709-731.

Akanji, B., Mordi, C. and Ajonbadi, H. A. (2020b), "The experiences of work-life balance, stress and coping lifestyles of female professionals: insights from a developing country", Employee Relations, Vol. 42 No. 4, pp. 999-1015.

Allen, J. A., Diefendorff, J. M. and Ma, Y. (2014), “The differences in emotional labour across cultures: A comparison of Chinese and U.S. service workers", Journal of Business Psychology, Vol. 28 No. 1, pp.10-25.

Ashforth, B. E. and Humphrey, R. H. (1993), "Emotional labour in service roles: The influence of identity”, Academy of Management Review, Vol. 18 No. 1, pp. 88-115.

Braun, V. and Clarke, V. (2006), "Using thematic analysis in psychology, Qualitative Research in Psychology, Vol. 3 No. 2, pp. 77-101.

Bowen, G. A. (2008), "Naturalistic inquiry and the saturation concept: a research note", Qualitative Research, Sage Publication, Vol. 8 No. 1, pp. 137-152.

Burgess, J., Connell, J. and McDonnell, A. (2018), "Finding Their Voice: Call Centre Employees in a Continuous Service Delivery Context", Employee Voice at Work, Vol. 4 No.2, pp. 169-181.

Butler, E. A., Lee, T. L. and Gross, J. J. (2007), Emotion regulation and culture: Are the social consequences of emotion suppression culture-specific? Emotion, Vol. 7 No. 1, pp. 30-48.

Cheung, R. Y. M. and Park, I. K. P. (2010), “Anger suppression, interdependent self-construal and depression among Asian American and European American college students", Cultural Diversity and Ethnic Minority Psychology, Vol. 16 No. 4, pp. 517-525.

Chicu, D., Pamies, M. M., Ryan, G. and Gross, C. (2019), "Exploring the influence of the human factor on customer satisfaction in call centres", BRQ Business Research Quarterly, Vol. 22 No. 2, pp. 83-95.

CIA World Factbook 2017, [online] www.cia.gov/library/publication/the-world factbook/geos. (accessed on 20/12/2019). 
Cohen J. A. (1960). Coefficient of agreement for nominal scales. Educational and Psychological Measurement, Vol. 6 No. 1, pp. 37-46.

Corley, K. G. and Giola, D. A. (2004), "Identity ambiguity and change in the wake of a corporate spin-off”, Administrative Science Quarterly, Vol. 49 No. 2, pp. 173-208.

D'Cruz, P. and Noronha, E. (2008), "Doing emotional labour: The experiences of Indian call centre agents", Global Business Review, Vol. 9 No. 1, pp. 131-147.

De Leersnyde, J., Boiger, M., and Mesquita, B. (2013), "Cultural regulation of emotion: individual, relational and structural sources", Frontiers in Psychology, Emotion Science, Vol. 4, No. 1, pp. 1-11.

Eid, M. and Diener, E. (2001), "Norms for experiencing emotions in different cultures: Inter39 and intranational differences", Journal of Personality and Social Psychology, Vol. 81 No. 5, pp. 869-885.

Fernie, S. and Metcalf, D. (1997). Hanging on the telephone: Payment systems in the New York sweetshops. Centre for Economics Performance, London School of Economics.

Ford, B. Q. and Gross, J. J. (2019), "Why beliefs about emotion matter: An emotion-regulation perspective", Current Directions in Psychological Science, Vol. 28 No. 1, pp. 74-81.

Haslam, D., Poniman, C., Filus, A., Sumargi, A. and Boediman, L. (2020), "Parenting Style, Child Emotion Regulation and Behavioural Problems: The Moderating Role of Cultural Values in Australia and Indonesia”, Marriage \& Family Review, Vol. 56 Issue 4, pp. 320-342.

Henchanova, R. M. (2013) "The call centre as a revolving door: a Philippine perspective, Personnel Review”, Vol. 42 Issue: 3, pp.349-365.

Hochschild, A. R. (1983). The managed heart: Commercialisation of human feelings. Berkeley: University of California Press.

Hofstede, G. (2001), Culture's Consequences: Comparing values, Behaviours, Institutions and Organisations across Nations, Sage, Thousand Oaks, CA.

Hultgren, A. K. (2017), "Vocatives as rationalized politeness: Theoretical insights from emerging norms in call centre service encounters", Journal of Sociolinguistics, Vol. 21 No.1, pp. 90-111.

Gain, N. (2011), "Development of emotional labour scale in Indian context", Vision, Vol. 15 No. 1, pp. 41-48.

Grandey, A. A. (2000), "Emotion regulation in the workplace: A new way to conceptualise emotional labour", Journal of Organisational Health Psychology, Vol. 5 No. 1, pp. 95-110.

Grandey, A., Rafaeli, A., Ravid, S., Wirtz, J. and Steiner, D. D. (2010), "Emotion display rules at work in the global service economy: the special case of the customer", Journal of Service Management, Vol. 21 No. 3, pp. 338-412.

Gross, J. J. (2015), "Emotion regulation: Current status and future prospects", Psychological Inquiry, Vol. 26 No. 1, pp. 1-26. 
Hochschild, A. R. (1983). The managed heart: Commercialization of human feeling, University of California Press: Berkley, CA

Hochschild, J. L. (1995), What is the American dream? In J. L. Hochschild (eds.), Facing up to the American dream: Race, class and the soul of the nation (pp. 15-38). Princeton University Press: Princeton.

Hofstede, G. (2001). Culture's consequences: Comparing values, behaviours, institutions and organisations across nations. Beverly Hills: Sage Publications.

Jaarsveld, D. and Poster, W. R. (2013), Emotional labour over the phone. In Grandey, A. A. Diefendorff, J. M. and Rupp, D. E. (Eds.), Emotional labour in the 21st century: Diverse perspectives on emotion regulation at work. New York, NY: Psychology Press/Routledge.

Jackson, T. (2004), Management change in Africa: A cross cultural perspective. London: Routledge.

Jeong, J. Y., Park, J and Hyun, H. (2019), "The role of emotional service expectation toward perceived quality and satisfaction: Moderating effects of deep acting and surface acting", Frontiers in Psychology, Vol. 10 Article 321, pp. 1-11.

Johnston, M. S., Johnston, G., Sanscartier, M. D. and Ramsay, M. (2019), “Get paid, get out': online resistance to call centre labour in Canada", New Technology, Work \& Employment, Vol. 34 Issue 1, pp.1-17.

Lincoln, Y. and Guba, E. (1985). Naturalistic inquiry, Sage: Beverly Hills, CA.

Ma, X., Tamir, M. and Miyamoto, Y. (2018), "A socio-cultural instrumental approach to emotion regulation: Culture and the regulation of positive emotions", Emotion, Vol. 18 No. 1, pp. 138-152.

Mann, S. (2007), "Expectations of emotional display in the workplace: An American/British comparative study", Leadership and Organisation Development Journal, Vol. 28 No. 6, pp. 552-570.

Matsumoto, D., Yoo, S. H. and Nakagawa, S. (2008), "Culture, emotion regulation and adjustment”, Journal of Personality and Social Psychology, Vol. 94 No. 6, pp. 925-937.

Matsumoto, D. (2007), “Culture, context, and behaviour. Journal of Personality” Vol. 75 No. 6, pp. 1285-1319.

Mastracci, S. \& Hsieh, C. (2016). Emotional labour and job stress in caring profession: Exploring universalism and particularism in construct and culture. International Journal of Public Administration, 39(14), 1125-1133.

Mesquita, B. and Delvaux, E. (2013), A cultural perspective on emotion labour. In A. Grandey, et al. (Eds.), Emotional labour in the 21st century. New York, NY, Routledge.

Mesquita, B., De Leersnyder, J. and Albert, D. (2014), The cultural regulation of emotions. In J, Gross (Eds.), Handbook of emotion regulation. The Guilford Press: US.

Miles, M. B., Huberman, A. M. and Saldana, J. (2014), Qualitative data analysis: A method sourcebook (3rd Ed.). Sage: United States. 
Morris, J. A. and Feldman, D. C. (1996), "The dimensions, antecedents and consequences of emotional labour”, Academy of Management Review, Vol. 21 No. 4, pp. 986-1010.

Mordi, C., Mmieh, F. and Ojo, S. (2013), “An exploratory study of manager's perspective of work life balance in Nigeria: A case analysis of the Nigerian banking sector", Thunderbird International Business Review, Vol. 55 No. 1, pp. 55-75.

Mukherjee, T. and Maheshwari, S. (2014), "The positive side of call centres: an Indian perspective", South Asian Journal of Global Business Research, Vol. 3 No. 1, pp. 36-53.

Narl1, N. and Akdemir, A. (2019), "Female Emotional Labour in Turkish Call Centres: Smiling Voices Despite Low Job Satisfaction”, Sociological Research Online, Vol. 24 No. 3, pp. 278296.

Nath, V. (2011), "Aesthetic and emotional labour through stigma: National identity management and racial abuse in offshored Indian call centres", Work, Employment and Society, Vol. 25 No. 4, pp. 709-725.

Nixon, C. S., Nelson, C. E. and Alabak, M. (2019), "Emotional labour, collectivism and strain: a comparison of Turkish and U.S. service employees", Journal on Work \& Stress, (in press) DOI: $10.1080 / 02678373.2019 .1598515$.

Patton, M. Q. (2015). Qualitative research and evaluation methods: Integrating theory and practice. (4th ed.), Los Angeles: Sage.

Pratt, M. G., Rockmann, K. W. and Kaufmann, J. B. (2006), Professional identity: The role of work and identity learning cycles in the customization of identity among medical residents. The Academy of Management Journal, Vol. 49 No. 2, pp. 235-262.

Pyramid research on the impact of mobile services in Nigeria, [online] www.pyramidresearch.com (accessed March, 2020).

Santos, A., Mustafa, J. M., and Gwi, T. C. (2015), "Trait emotional intelligence, emotional labour, and burnout among Malaysian HR professionals”. Management Research Review, Vol. 38 No. 1, pp. 67-88.

Saunders, M., Lewis., P. and Thornhill, A. (2015). Research methods for business students (7th ed.). London, England: Prentice Education Limited.

Subramanian, D. and Suquet, J. (2018), "Unpacking the service triangle: Arranging power relations between frontline occupations", Work and Occupations, Vol. 45 No. 1, pp. 38-81.

Tsai, J. L., Knutson, B. and Fung, H. H. (2006), “Cultural variation in affect valuation”, Journal of Personality and Social Psychology, Vol. 90, No. 4, pp. 288-307.

Tsang, S. J. (2019), “Cognitive discrepancy, dissonance, and selective exposure” Media Psychology, Vol. 22 Issue: 3, pp. 394-417.

Von-Scheve, C. (2012), "Emotion regulation and emotion work: Two sides of the same coin?" Frontiers of Psychology, Vol. 3 No. 4, pp. 1-10.

Wegge, J., Van Dick, R. and von Bernstorff, C. (2010), "Emotional dissonance in call centre work", Journal of Managerial Psychology, Vol. 25 No. 6, pp. 596-619. 
Wice, M., Matsui, T., Tsudaka, G., Karasawa, M. and Miller, J. G. (2019), "Verbal display rule knowledge: A cultural and developmental perspective", Cognitive Development, Vol. 52 No. 10/12, pp. 91-106. 


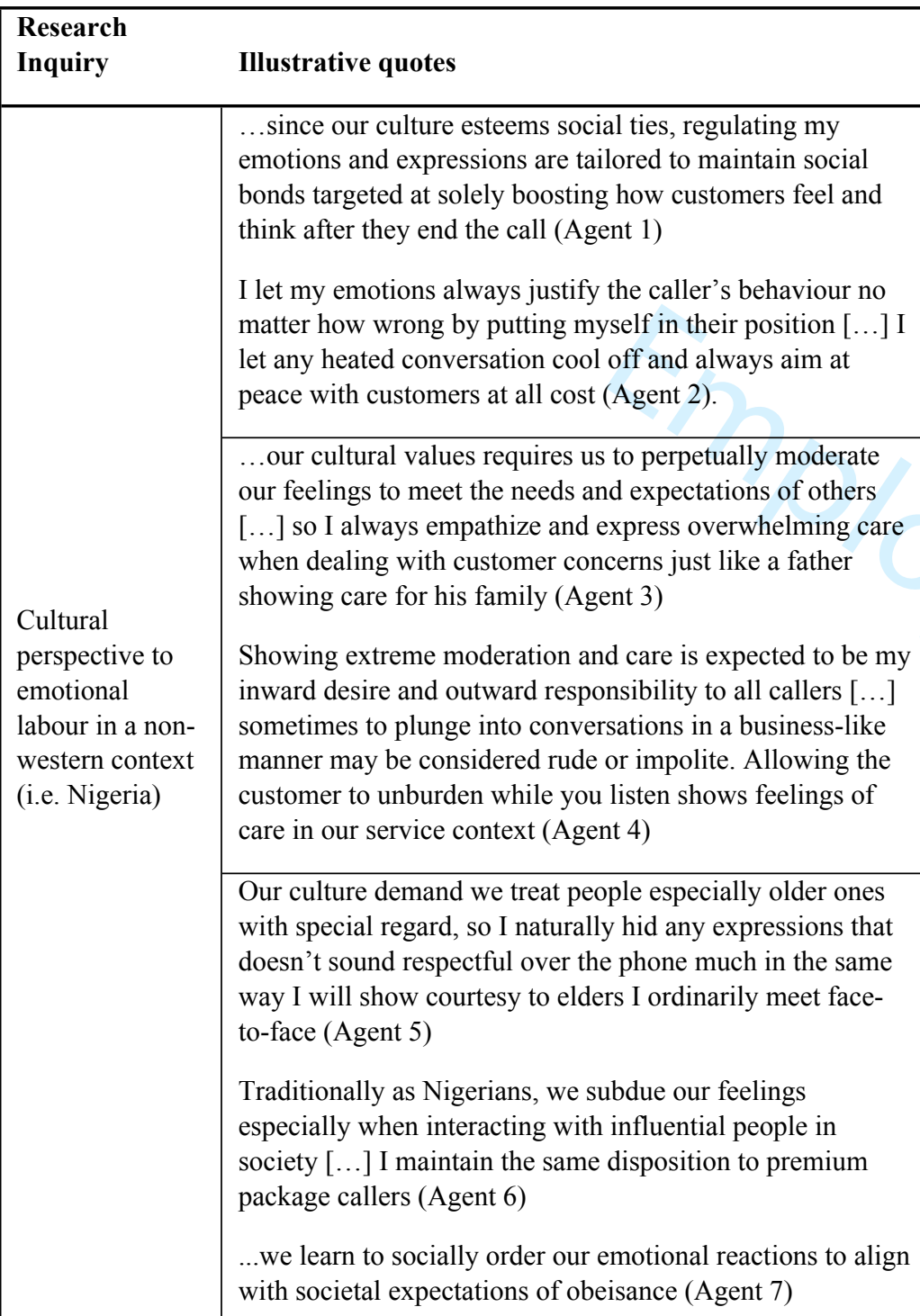

Figure 1: Qualitative data analysis

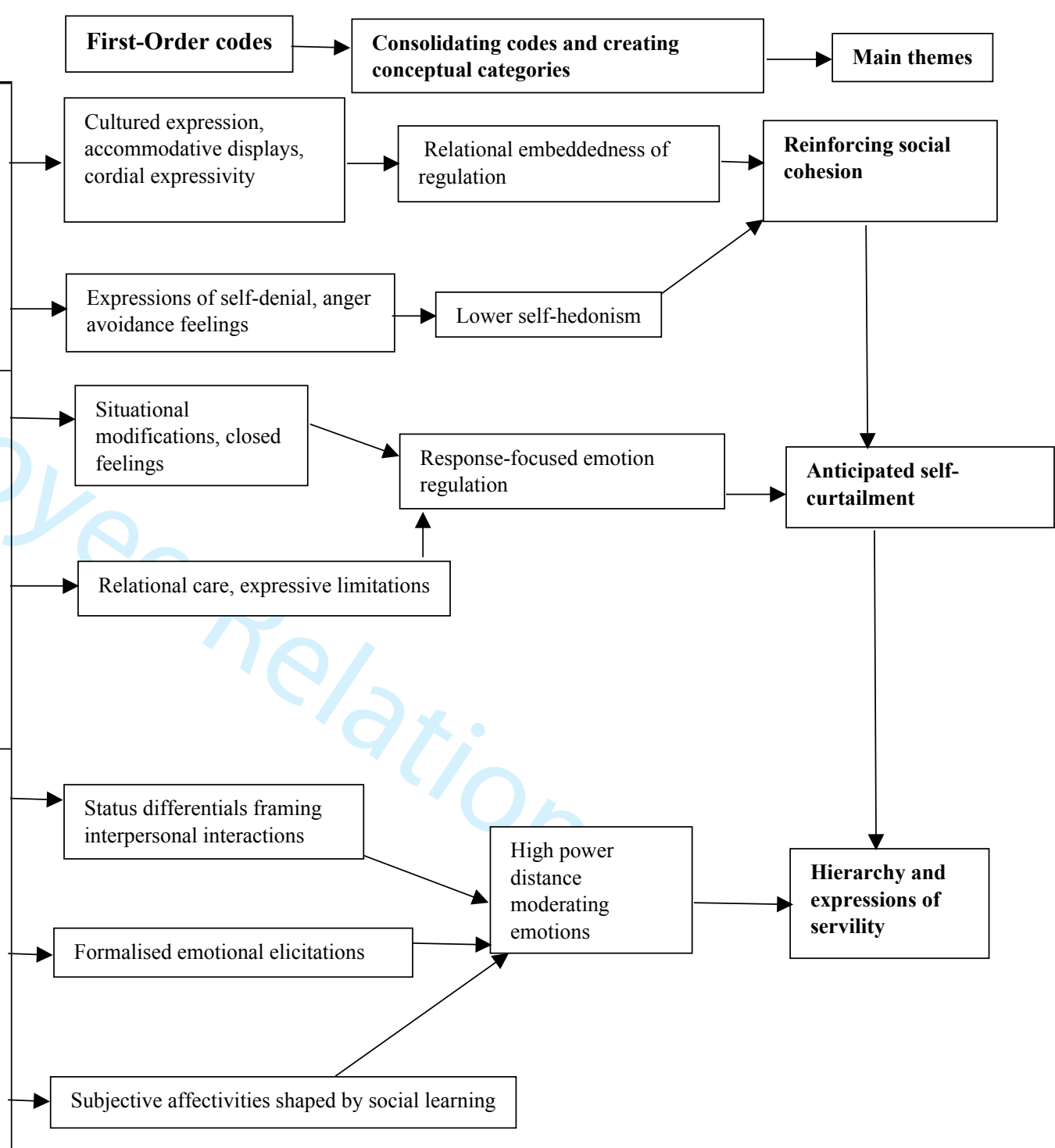


Source: Researchers' findings (2020). 